\title{
$\mathrm{CiSj}$
}

\section{DEVELOPING THE ADAPTIVE KNOWLEDGE MANAGEMENT IN CONTEXT OF ENGINEERING COMPANY PROJECT ACTIVITIES}

\author{
Olha Sherstiuk ${ }^{1)}$, Oleksii Kolesnikov ${ }^{2)}$, Viktor Gogunskii ${ }^{3)}$, Kateryna Kolesnikova ${ }^{2)}$ \\ 1) Odessa National Maritime University, Odessa, Mechnikova Str. 34, Ukraine, 65029, \\ olusha972@gmail.com, http://www.onmu.odessa.ua \\ 2) Taras Shevchenko National University of Kyiv, Kyiv, Volodymyrska Str. 60, Ukraine, 01033 \\ akoles78@gmail.com, amberk4@gmail.com, http://www.univ.kiev.ua/ua/ \\ 3) Odessa National Polytechnic University, Odessa, Avenue Shevchenko, 1, Ukraine, 65044, vgog@i.ua, https://opu.ua/
}

Paper history:

Received 8 September 2020

Received in revised form 9 October 2020

Accepted 23 November 2020

Available online 30 December 2020

Keywords:

adaptive knowledge acquisition;

competence level;

adaptation potential;

Cobb and Douglas's model;

Harrington's desirability function.

\begin{abstract}
The concept of Adaptive Knowledge Management is an approach essentially increasing the effectiveness of project participants in their processes that are unpredictable or initialized in advance by unknown events. The research deals with developing the strategy of proactive formation of project team competencies within an industrial enterprise. The most important component of this strategy is the formation of "knowledge coordinators" who are responsible for knowledge management and the creation of training and knowledge sharing regulations. On the basis of this strategy the method of determining the adaptation potential of team members is developed, which is based on the assessment of project task implementation of different complexity, taking into account the identifiers of continuous knowledge growth, which allows predicting the possibilities of increasing the competence level and determining the sustainability of project team members' knowledge. This method can be used to form a project team considering the accumulated experience and knowledge of its participants.
\end{abstract}

Copyright $(\mathbb{C}$ Research Institute for Intelligent Computer Systems, 2020. All rights reserved.

\section{INTRODUCTION AND RELATED WORKS}

Over the past decades, learning and knowledge have become a key factor of success in international competition, resulting in intangible resources that have outstripped the importance of material and visible ones. The introduction of practices and knowledge management (KM) gives industrial enterprises the opportunity to maximize the value of the knowledge they own as well as the ability to learn, to adapt to changes in external environment, to go ahead of competitors.

Nowadays the dynamism of the modern labor market forms a request not only for knowledge, but also for competence and skills of specialists. The only limited resource is time for training and for adapting to constant changes.

Along with the known processes of knowledge management as a set of processes for collecting, creating, processing, generalizing, disseminating and using knowledge, it is necessary to resolve the essential contradiction of the learning systems with respect to effectiveness of communications between the knowledge carrier and the trainee [1-3]. Currently, interest has shifted from training systems based on the traditional model of knowledge acquisition to an individually oriented adaptive model. The relevance of such a model is stimulated by the introduction of personality and competencyoriented models of acquiring knowledge. The development and implementation of such models, in turn, require the development of an adaptive learning system based on a competency approach.

The concept and nature of knowledge are at the center of the interests of the two theories, both learning and knowledge management. In articles [4, 5] knowledge is linked with learning. Knowledge is defined as "the possibility or potential for action or decision-making by a person, group or organization". In turn, learning is a process leading to changes in understanding, decisions or actions. 
Most authors distinguish two main categories of knowledge - explicit and hidden. For example, in [6-9] it is pointed out that explicit knowledge can be described in a formal language and transferred to other people, and the hidden can be characterized as personal knowledge associated with personal experience and such intangible factors as personal beliefs, perspectives and values.

However, existing models and methods above do not identify the self-regulation parameters of the system, especially if we take into account the factors influencing on the level of competence of the project team members.

Therefore a goal of this paper is to develop a method of forming a project team based on adaptive knowledge acquisition process including a change of the competence level during several projects within an industrial enterprise.

In accordance with the set goal the following research objectives are identified:

1. To develop a strategy of proactive formation of project team competencies within an industrial enterprise.

2. To develop integral method of estimating the adaptation potential of the project team.

3. To determine the self-regulatory parameters of the system.

\section{MATERIALS AND METHODS}

The need to develop a knowledge management system at the scale of a single enterprise was prompted by an analysis of the changes taking place in the world economy and the economy of Ukraine, such as:

- globalization processes have intensified the flow of material, financial and intellectual resources between countries;

- the collapse of the planned socialist economy significantly changed the situation for Ukrainian enterprises (both external and internal), the incompleteness of market transformation increased their instability and vulnerability to competitors;

- the restructuring of corporate governance towards a more active use of knowledge increases the competitiveness of the company;

- the level of support and use of knowledge in domestic enterprises is still significantly inferior to the global and European level.

Given these trends, common approaches to building a knowledge management system in the engineering company are applied.

1. Knowledge is information, accumulated experience and competencies that ensure successful targeted economic activity and enterprise development. This means that this can only be useful information.
2. Knowledge is an organic part of corporate culture, since it consists of micro models of various processes (technological, industrial, marketing, etc.), in which information is presented in a concentrated and adapted form.

3. The struggle for the customer leads to the individualization of demand and consumption. This usually requires the manufacturer to customize products and services. Knowledge also seeks to "individualize", which leads to a sharp improvement in implicit (non-codified) knowledge. As a result, the labor market is fundamentally transforming: instead of the market for "working hands", it becomes a market for "smart heads" capable of generating new knowledge.

4. Two stages of work are planned:

- on the first stage, the main role will be played by the processes of collecting, processing and transmitting information: each employee will gain access to its repositories (global and corporate);

- on the second stage (it can be called "creative cognition") the employees, having understood the experience gained, will themselves begin to create new knowledge.

5. Knowledge as a resource should be an object of accounting, monitoring, accumulation, storage and periodic updating.

6. Knowledge is an integral indicator, which is a corporate intellectual potential.

7. Knowledge is objectified in various forms such as an independent product (for example, a marketing project); a final consumption item (for example, cost analysis data); production resource used in the manufacture of products (for example, technology of the heat treatment process of the roll); means of communication with the consumer (for example, an advertising campaign project); a resource for supporting management decision-making (for example, an analytical review of the market for certain resources); the resource of consolidation of the team (for example, the values of corporate culture), etc.

8. The rational correlation of the basic concepts of "enterprise" and "knowledge" is found. In the basic version of neoclassical theory, an enterprise is considered as an "information processor" in which resources are allocated taking into account information signals coming from outside. The cognitive theory of the enterprise is adopted: it assumes that organizations are inherent in the ability to perceive and process external information. In this theory, an enterprise is considered as a "knowledge processor", combining new knowledge with existing knowledge, and also forming new competencies the basis of competitiveness. 


\subsection{THE DEVELOPMENT OF THE PROACTIVE FORMATION OF THE PROJECT TEAM COMPETENCES WITHIN THE ENGINEERING COMPANY}

To achieve the goal of accelerated evolutionary development of the engineering company to become a self-learning intellectual organization, a strategy has been developed for the proactive development of employees' competences (Fig. 1). The most important component of this strategy is the formation of a new category of specialists interdisciplinary "knowledge coordinators" who are responsible not only for knowledge management, but also for the creation of training regulations and knowledge sharing regulations.

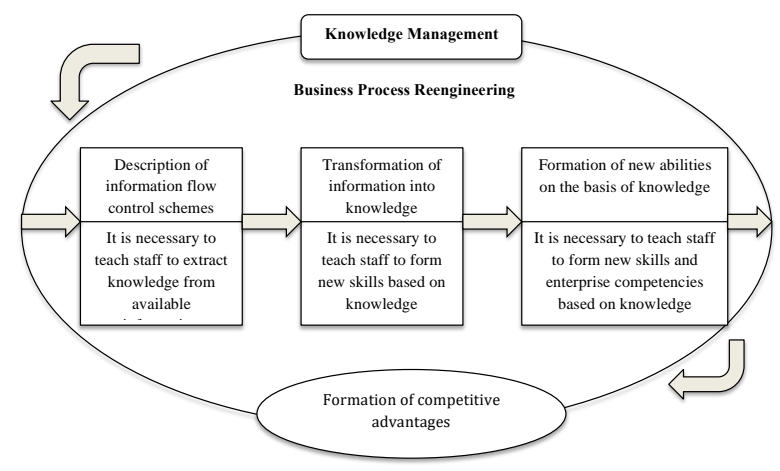

Fig. 1 - Strategy of proactive formation of the project team competencies within an industrial enterprise

A strategy of proactive formation of the project team competencies within an industrial enterprise states that it is necessary to manage the selftransformation of knowledge, helping to discard knowledge that has lost relevance, teaching new knowledge acquisition, creating new applications and introducing innovations into an organized process.

Adaptive knowledge acquisition involves analyzing the course of acquiring knowledge (learning) and evaluating the criterion of transition to a new competence level. Adaptive knowledge acquisition is possible only when the criteria are determined and their preliminary testing is conducted for the purpose of assessing the validity and complexity that delimits the abilities for the levels (cycles) of adaptive knowledge acquisition [10-15].

\subsection{THE INTEGRAL METHOD OF ESTIMATING THE ADAPTATION POTENTIAL OF THE PROJECT TEAM}

Adaptive knowledge acquisition by the participants of the project team is carried out with the help of the given level of complexity of the project task, as well as the mechanism of adaptation. With the asynchronous interaction of project team members, the process of acquiring knowledge takes place at a pace due to the competence level [16]; therefore, it is necessary adaptively to take into account the achieved level of knowledge.

Adaptive knowledge acquisition by project team participants is usually realized on the basis of the hypothesis of providing the presentation of the project task at $50 \%$ of the complexity level [17], which follows from the fact that the easy tasks do not possess the developing potential, and very complex, on the contrary, reduce the motivation of team members. This level is accepted as the optimal (rational), and the acquisition of knowledge aims to adapt the process of acquiring knowledge to such a level in a collective knowledge acquisition. In the general case, it can be assumed that Cobb and Douglas's model is as follows:

$$
y(x)=\prod_{i=1}^{n} y_{i}^{\alpha_{i}(x)}
$$

where $x=\left(x_{1}, x_{2}, \ldots, x_{n}\right)$ - parameters influencing the result (gaining knowledge);

$y \quad(x)$ - generalized result of growth of knowledge;

$\alpha_{i}$ - indicator of adaptation possibilities.

If $y(x)$ is understood as learning potential, under $y_{i}$ is $i$-factor of the growth of this potential, then such functions can serve as models for increasing the selforganization of the learning process of project team members. Parameters $\left(x_{1}, x_{2}, \ldots, x_{n}\right)$ are integrally aimed at effective rational adaptation, $\alpha_{i}$ is the importance of the considered knowledge acquisition parameter or the parameter of self-regulation (adaptation possibilities) of the participant (acquiring knowledge) from this factor $i$. These parameters are determined according to the target orientation of acquiring knowledge, its basic parameters for a specific period.

For example, $x_{1}, x_{2}-$ are, respectively, the quality and orientation to the result.

The optimum, lower and upper values can significantly depend on the target setting. For example, optimal values of the parameter are selected using expert estimates or from statistical materials using statistical and mathematical methods. The number of parameters can vary and the more they are, the closer the task to the real environment is. It is important to be able to identify the unknown parameters of the self-organization of the $\alpha_{i}$ system according to the observations of the participants in the team $x_{i}, i=1,2, \ldots, m$, since these 
parameters are universal, reflecting the basic parameters that characterize the various corresponding reactions to one or another script for acquiring knowledge.

It is important to note that the growth parameter $\alpha_{i}$ will already show the self-organization of the system and integrate the influence of all parameters. The following generalized multiplicative type integral model that describes the contribution of each parameter to the overall system response is considered as follows:

$$
\Delta y=\prod_{k=1}^{m}\left(\frac{y_{k}(x)-y_{k}^{\text {low }}}{y_{k}^{0}-y_{k}^{\text {low }}}\right)^{\alpha_{k}}\left(\frac{y_{k}^{\text {top }}-y_{k}(x)}{y_{k}^{\text {top }}-y_{k}^{0}}\right)^{-\alpha_{k} \frac{y_{k}^{\text {top }}-y_{k}^{0}}{y_{k}^{0}-y_{k}^{\text {low }}}}
$$

where $y_{k}$ - current values of parameters (points of the taxonomy of competencies when participating in the current project);

$y^{\text {low }}-$ lower values $y_{k}$;

$y_{k}^{0}$-optimal values $y_{k}$;

$y^{\text {top }}$ - upper values $y_{k}$;

$\alpha_{k}$ - the identifier of the constant growth of knowledge;

$\Delta y$ - adaptation potential.

Such models relate to models of Cobb and Douglas's production type, and are used to predict evolutionary multifactorial systems.

Identified parameters will allow predicting the adaptability of the system, the stability of the project team members' knowledge.

Consequently, the task of identifying the coefficients $\alpha_{k}$ or, in other words, the task of determining the parameters of the system selfregulation, on which the specified potential directly depends, is set.

The notations are entered:

$$
a_{k i}=\frac{y_{k}(x)-\underline{y_{k}}}{y_{k}^{0}-\underline{y_{k}}} ; b_{k i}=\frac{\overline{y_{k}}-y_{k}(x)}{\overline{y_{k}-y_{k}^{0}}} ; c_{k}=\frac{\overline{y_{k}}-y_{k}^{0}}{y_{k}^{0}-\underline{y_{k}}} ;
$$

Now, taking into account the above notation, Eq. (2) is written in the form:

$$
\Delta y=\prod_{k=1}^{m} a_{k i}^{\alpha_{k}} b_{k i}^{-\alpha_{k} c_{k}} .
$$

The function with parameters $\alpha_{\mathrm{k}}$ can be linearized. To do this, the two parts of Eq. (4) are written in logarithmic form:

$$
\begin{aligned}
& \ln \Delta y=\sum_{k=1}^{m} \ln a_{k i}^{\alpha_{k}} b_{k i}^{-\alpha_{k} c_{k}}=\sum_{k=1}^{m}\left(\ln a_{k i}^{\alpha_{k}}-c_{k} \ln b_{k i}^{\alpha_{k}}\right)= \\
& =\sum_{k=1}^{m} \alpha_{k}\left(\ln a_{k i}-c_{k} \ln b_{k i}\right)=\sum_{k=1}^{m}\left(\ln \frac{a_{k i}}{b_{k i}^{c_{k}}}\right) \alpha_{k}
\end{aligned}
$$

So, Eq.(6) is obtained:

$$
\ln \Delta y=\sum_{k=1}^{m} \alpha_{k} \ln P_{k i},
$$

where

$$
P_{k i}=\frac{a_{k i}}{b_{k i}^{c_{k}}} .
$$

The Eq. (6) is linear with respect to the parameter $\alpha_{k}$.

Then, the experimental values of $\Delta y_{i}^{e}$ are used. Using the least squares method, the following functional is constructed:

$$
\Phi\left(\alpha_{1}, \alpha_{2}, \ldots, \alpha_{m}\right)=\sum_{i=1}^{N}\left\{\sum_{k=1}^{m} \alpha_{k} \ln P_{k i}-\ln \Delta y_{i}^{e}\right\}^{2} \Rightarrow \min .
$$

To determine the minimum of the functional $F(\alpha)$ for the parameters $\alpha_{1}, \alpha_{2}, \ldots, \alpha_{m}$ it is necessary to take its separate derivatives according to these parameters and to equate them to zero:

$$
\left\{\begin{array}{l}
\frac{\partial \Phi}{\partial \alpha_{1}}=0 \\
\frac{\partial \Phi}{\partial \alpha_{2}}=0 \\
\frac{\partial \Phi}{\partial \alpha_{m}}=0
\end{array} .\right.
$$

Next, finding derivatives of Eq. (8) and substituting them in Eq. (9) it is obtained:

$$
\left\{\begin{array}{l}
\frac{\partial \Phi}{\partial \alpha_{1}}=2 \sum_{i=1}^{N}\left\{\sum_{k=1}^{m} \alpha_{k} \ln P_{k i}-\ln \Delta y_{i}^{e}\right\} \ln P_{1 i}=0 \\
\frac{\partial \Phi}{\partial \alpha_{2}}=2 \sum_{i=1}^{N}\left\{\sum_{k=1}^{m} \alpha_{k} \ln P_{k i}-\ln \Delta y_{i}^{e}\right\} \ln P_{2 i}=0 \\
\frac{\partial \Phi}{\partial \alpha_{m}}=2 \sum_{i=1}^{N}\left\{\sum_{k=1}^{m} \alpha_{k} \ln P_{k i}-\ln \Delta y_{i}^{e}\right\} \ln P_{m i}=0
\end{array}\right.
$$

Consequently, a system of linear algebraic equations of the type is obtained: 


$$
\left\{\begin{array}{l}
\sum_{i=1}^{N}\left\{\sum_{k=1}^{m} \alpha_{k} \ln P_{k i}-\ln \Delta y_{i}^{e}\right\} \ln P_{1 i}=0 \\
\sum_{i=1}^{N}\left\{\sum_{k=1}^{m} \alpha_{k} \ln P_{k i}-\ln \Delta y_{i}^{e}\right\} \ln P_{2 i}=0 . \\
\sum_{i=1}^{N}\left\{\sum_{k=1}^{m} \alpha_{k} \ln P_{k i}-\ln \Delta y_{i}^{e}\right\} \ln P_{m i}=0
\end{array}\right.
$$

The system is transformed:

$$
\left\{\begin{array}{l}
\sum_{i=1}^{N}\left[\ln P_{1 i}\left(\alpha_{1} \ln P_{1 i}+\alpha_{2} \ln P_{2 i}+\ldots+\alpha_{m} \ln P_{m i}-\ln \Delta y_{i}^{e}\right)\right]=0 \\
\sum_{i=1}^{N}\left[\ln P_{2 i}\left(\alpha_{1} \ln P_{1 i}+\alpha_{2} \ln P_{2 i}+\ldots+\alpha_{m} \ln P_{m i}-\ln \Delta y_{i}^{e}\right)\right]=0 \\
\sum_{i=1}^{N}\left[\ln P_{m i}\left(\alpha_{1} \ln P_{1 i}+\alpha_{2} \ln P_{2 i}+\ldots+\alpha_{m} \ln P_{m i}-\ln \Delta y_{i}^{e}\right)\right]=0
\end{array},\right.
$$

or

$$
\left\{\begin{array}{l}
\alpha_{1} \sum_{i=1}^{N} \ln P_{1 i} \ln P_{1 i}+\ldots+\alpha_{m} \sum_{i=1}^{N} \ln P_{1 i} \ln P_{m i}=\sum_{i=1}^{N} \ln \Delta y_{i}^{e} \ln P_{1 i} \\
\alpha_{2} \sum_{i=1}^{N} \ln P_{2 i} \ln P_{1 i}+\ldots+\alpha_{m} \sum_{i=1}^{N} \ln P_{2 i} \ln P_{m i}=\sum_{i=1}^{N} \ln \Delta y_{i}^{e} \ln P_{2 i} \\
\alpha_{m} \sum_{i=1}^{N} \ln P_{m i} \ln P_{1 i}+\ldots+\alpha_{m} \sum_{i=1}^{N} \ln P_{m i} \ln P_{m i}=\sum_{i=1}^{N} \ln \Delta y_{i}^{e} \ln P_{m i}
\end{array}\right.
$$

The coefficients of the received symmetric system of linear algebraic equations are determined by Eq. (14) and Eq. (15):

$$
\begin{aligned}
s_{k i} & =\sum_{i=1}^{N} \ln P_{k i} \ln P_{j i},(k, j=\overline{1, m)} ; \\
g_{k} & =\sum_{i=1}^{N} \ln \Delta y_{i}^{e} \ln P_{k i},(k=\overline{1, m)} .
\end{aligned}
$$

To solve the obtained symmetric system of linear algebraic equations, the square root method is applied.

The square root method is often used to solve a linear system:

$$
S \alpha=g \text {, }
$$

with a symmetric matrix $S: s_{k j}=s_{j k}$.

The system is implemented in two stages.

Direct solution. A matrix $S$ can be expressed in the form of a product of two mutually transposed triangular matrices (where $S=T^{\prime} T$ ):

$$
\begin{aligned}
T & =\left(\begin{array}{cccc}
t_{11} & t_{12} & \ldots & t_{1 m} \\
0 & t_{22} & \ldots & t_{2 m} \\
\ldots & \ldots & \ldots & \ldots \\
0 & 0 & \ldots & t_{m m}
\end{array}\right), \\
T^{\prime \prime} & =\left(\begin{array}{cccc}
t_{11} & 0 & \ldots & 0 \\
t_{12} & t_{22} & \ldots & 0 \\
\ldots & \ldots & \ldots & \ldots \\
t_{1 m} & t_{2 m} & \ldots & t_{m m}
\end{array}\right) .
\end{aligned}
$$

By multiplying the matrix $T$ and $T^{\prime}$ and equating to the matrix $S$, Eq. (19), Eq. (20), Eq. (21) and Eq. (22) for determining $t_{i j}$ are obtained:

$$
\begin{gathered}
t_{11}=\sqrt{s_{11}}, \\
t_{1 j}=\frac{s_{1 j}}{t_{11}}(\mathrm{j}>1), \\
t_{i i}=\sqrt{s_{i i}-\sum_{k=1}^{i-1} t_{k i}^{2}}(1<\mathrm{i} \leq \mathrm{m}), \\
t_{i j}=\frac{s_{i j}-\sum_{k=1}^{i-1} t_{k i} t_{k j}}{t_{i i}} \quad(\mathrm{i}<\mathrm{j}) .
\end{gathered}
$$

After the matrix $\mathrm{T}$ is found, the system $\mathrm{S} \alpha=\mathrm{g}$ is replaced with two equivalent systems with triangular matrices:

$$
\begin{aligned}
& T^{\prime} z=g ; \\
& T a=z .
\end{aligned}
$$

Reverse solution. From these two systems it is found:

$$
\begin{gathered}
z_{1}=\frac{g_{1}}{t_{11}} ; z_{i}=\frac{g_{i}-\sum_{k=1}^{i-1} t_{k i} z_{k}}{t_{i i}}, i=2,3, \ldots, m, \\
\alpha_{m}=\frac{z_{m m}}{t_{m m}}, \alpha_{i}=\frac{z_{i}-\sum_{k=i+1}^{m} t_{i k} \alpha_{k}}{t_{i i}} \quad i=m-1, \ldots, 1 .
\end{gathered}
$$

So, the unknown coefficients $\alpha_{k}, k=\overline{1, m}$ are determined.

After that a forecast by model (2) can be made.

It is important to note that the statistics can be given at an uneven interval. In this case, the interpolation of the array $z_{k}$ is used in order to find the increment through even intervals. The linear interpolation method can be used. 
The values of $\alpha_{i}$ make it possible to predict the adaptation capabilities of project team members.

\section{RESULTS}

As factor values, standardized points of competence of the team members were used, which were necessary for tasks of varying complexity in three projects within the engineering company, during which an adaptive knowledge acquisition system was introduced. The set of competencies is defined using the standard IPMA ICB 4.0. Standardized points of competencies of the project manager are given in Table 1. Of the 29 competencies given in the IPMA ICB 4.0 standard, 12 experts select those that are necessary to perform certain project tasks, using functional and competence matrix. The result of statistical processing by experts of the functional competency matrix is the selection of competencies by groups Practice, People and Perspective. When forming the necessary set of competencies, the range method was used [18].

Standardized scores for the other three participants of the project team are similarly calculated.

Table 1. The standardized points for each project manager's competence.

\begin{tabular}{|c|c|c|c|c|c|}
\hline Competence & $\begin{array}{l}\text { Value } \\
\text { of } \\
\text { comp } \\
\text { etenc } \\
\text { e } \\
\text { points } \\
\text { for } \\
\text { partic } \\
\text { ipatio } \\
\text { n in } \\
\text { proje } \\
\text { ct } 1 \\
\left(y^{l o w}\right)\end{array}$ & $\begin{array}{l}\text { Value } \\
\text { of } \\
\text { comp } \\
\text { etenc } \\
\mathrm{e} \\
\text { points } \\
\text { for } \\
\text { partic } \\
\text { ipatio } \\
\mathrm{n} \quad \text { in } \\
\text { proje } \\
\text { ct } 2 \\
\left(y_{k}\right)\end{array}$ & $\begin{array}{l}\text { Value } \\
\text { of } \\
\text { comp } \\
\text { etenc } \\
\mathrm{e} \\
\text { points } \\
\text { for } \\
\text { partic } \\
\text { ipatio } \\
\mathrm{n} \quad \text { in } \\
\text { proje } \\
\text { ct } 3 \\
\left(y^{t o p}\right)\end{array}$ & $\begin{array}{l}\text { Opt } \\
\text { imu } \\
\mathrm{m} \\
\text { valu } \\
\mathrm{e} \\
\left(y_{k}^{o}\right)\end{array}$ & $\begin{array}{l}\text { Identi } \\
\text { fier } \\
\text { of the } \\
\text { const } \\
\text { ant } \\
\text { growt } \\
\text { h of } \\
\text { know } \\
\text { ledge } \\
\left(\alpha_{k}\right)\end{array}$ \\
\hline Strategy & 2 & 3 & 7 & 6 & 0,23 \\
\hline Stakeholders & 4 & 6 & 8 & 6 & 0,18 \\
\hline $\begin{array}{l}\text { Risk and } \\
\text { opportunity }\end{array}$ & 2 & 3 & 7 & 6 & 0,14 \\
\hline $\begin{array}{l}\text { Governance, } \\
\text { structures } \\
\text { and } \\
\text { processes }\end{array}$ & 4 & 7 & 8 & 6 & 0,11 \\
\hline Time & 2 & 3 & 7 & 6 & 0,08 \\
\hline Negotiation & 5 & 7 & 8 & 6 & 0,06 \\
\hline Scope & 2 & 3 & 7 & 6 & 0,05 \\
\hline $\begin{array}{l}\text { Change and } \\
\text { transformati } \\
\text { on }\end{array}$ & 3 & 4 & 7 & 6 & 0,04 \\
\hline Teamwork & 4 & 7 & 8 & 6 & 0,03 \\
\hline $\begin{array}{l}\text { Results } \\
\text { orientation }\end{array}$ & 5 & 7 & 8 & 6 & 0,02 \\
\hline Quality & 5 & 6 & 7 & 6 & 0,02 \\
\hline
\end{tabular}

\begin{tabular}{|l|c|c|c|c|c|}
\hline $\begin{array}{l}\text { Conflict and } \\
\text { crisis }\end{array}$ & 5 & 7 & 7 & 6 & 0,01 \\
\hline $\begin{array}{l}\text { Compliance, } \\
\text { standards } \\
\text { and } \\
\text { regulation }\end{array}$ & 5 & 7 & 8 & 6 & 0,01 \\
\hline Leadership & 4 & 7 & 7 & 6 & 0,01 \\
\hline $\begin{array}{l}\text { Requirement } \\
\text { s and } \\
\text { objectives }\end{array}$ & 5 & 7 & 8 & 6 & 0,01 \\
\hline
\end{tabular}

Thus, the current values of the parameters $y_{k}$ (the value of the points of competency while participating in the current project) were determined, the optimal values $y_{k}^{o}$, the lower and upper values $y^{\text {low }}$ and $y^{\text {top }}$ were set (the value of the points of competency in participation in the previous and subsequent projects). The parameters of selfregulation (adaptation capabilities) of the team members $\alpha_{k}$ are calculated using the standard mathematical package MathCAD.

The results of the adaptation potential of the participants in the project team $\Delta y$ are given in Table 2.

\section{Table 2. Assessment of the project team members'} adaptation potential.

\begin{tabular}{|l|l|}
\hline Team member & $\begin{array}{l}\text { Adaptation } \\
\text { potential }(\Delta y)\end{array}$ \\
\hline Project manager & 0,46 \\
\hline Administrator & 0,41 \\
\hline Project engineer & 0,68 \\
\hline Project manager's assistant & 0,39 \\
\hline
\end{tabular}

These results show that the project engineer has the highest adaptation potential and the project manager assistant has the lowest one, i.e., the project engineer has more adaptation possibilities to increase his competence level.

The level of adaptation potential can be determined on the basis of Harrington's generalized desirability function (Fig. 3). The $X$-axis is the scale of the adaptation potential of the team members from 0 to 1 , which are converted into values from -2 to +3 . The desirable scale is divided into five intervals ranging from 0 to 1 , each of which is determined by experts in the fuzzy expression: [0; 0.2] - "very low desirable", [0; 0.37] - "low desirable", [0,37;0,63] - "moderately desirable", $[0,63 ; 0,8]$ - "highly desirable", $[0,8 ; 1]$ - "very highly desirable". In this case, if the "best" of all values of the adaptation potential is assigned a score of "+3", and "worst" - "-2", then all others will be placed between them, forming a sequence of values [19]. Converting them into partial $y$ indicators, the desirability coefficients for this comparative parameter being represented on the $d$-axis of desirability are obtained. 


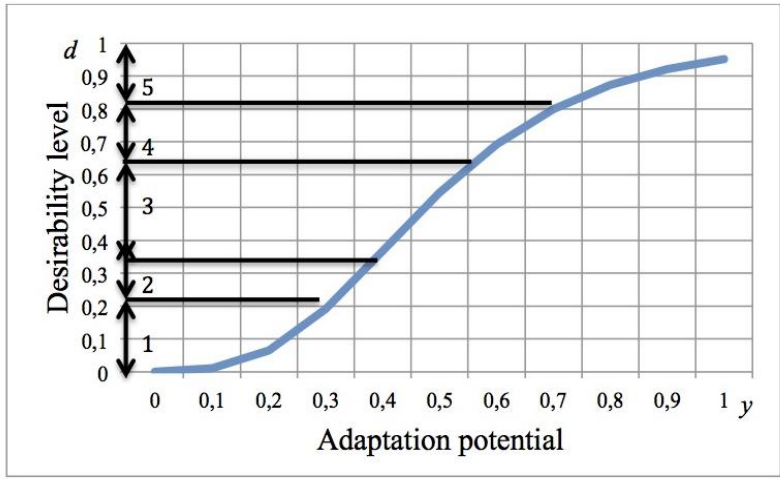

Figure 2 - Harrington's desirability function: 1 «very low desirable»; 2 - «low desirable»; 3 «moderately desirable»; 4 - «highly desirable»; 5 «very highly desirable».

Thus, according to the given graph, it can be concluded that the adaptive potential of the project manager, his assistant and administrator corresponds to the interval 3 - "moderately desirable" and the adaptive potential of the project engineer - interval 4 - "highly desirable".

Thus, the application of the adaptation design system is bi-directional. On the one hand, the educational system on behalf of the head and the project team, with their methods, forms, content and technologies actively adapts to the individual characteristics of one member of the team. On the other hand, the participant himself adapts to this system resulting in qualitative changes in his psychophysiological and social characteristics, which affects the project activity outcome [20, 21]. Therefore, when developing a project team based on a competency approach, an adaptive system for acquiring knowledge of team members can be used to form key competencies.

\section{DISCUSSION}

Comparing the received results with existing works, the research of adaptive learning in $[1,4,5]$ mainly focused on improving team learning achievements based only on single-source of personalization information, such as learning style, cognitive style or learning achievement. In article [6], an innovative adaptive learning approach is proposed, which is based on two main sources of personalization information: learning behavior and personal learning style. Based on article [2] it can be confirmed by the method determining adaptation potential that project complexity is as an antecedent of team-level absorptive capacity and demonstrated how each dimension of absorptive capacity has unique determinants and outcomes. The approach in the above research can be similar to the approach called Knowledge Configuration Model [3], which allows for acquisition, traceability, re-use and consistency of explicit knowledge used in configuration. The method for determining the level of staff competence is based on the fact that success of the project corresponds to the competence level. For an overall assessment of staff competence, it is necessary to divide the project into operations, which assessment is performed on the basis of process regulations [17]. In the above research, the values of all necessary competences are defined in each of three projects. Based on them, the identifier of the constant growth of knowledge is calculated.

The mathematical model of the competencebased learning-teaching process is proposed in [20]. The model integrates three models: a knowledge representation model (based on the ontological approach), a motivation model (as a behavioralincentive model) and a servicing model (in a form of the queuing model). The proposed integrated model allows controlling the learning-teaching process on different levels of management similar to the above research. However, in [3] the adaptation potential is not considered.

\section{CONCLUSIONS}

The obtained results show that the introduction of the adaptive learning system of the project team allows increasing in the level of competence of project team participants on individual trajectories. The influence of an adaptive knowledge management system on the formation of key competencies is objective and does not depend on the specificity of the project and the intentions of the project team members.

According to the assigned functional roles, each participant in the project team must have a certain set of competencies to carry out the work in the project. Due to the adaptive learning system, project team participants increase the level of knowledge on the individual trajectories. This can be seen, in particular, in Table 1 - the level of competence of the project manager increases within the third project, due to its adaptive capacity $\left(\alpha_{k}\right)$ and, according to Harrington's generalized desirability function, satisfies the level "satisfactorily". According to calculations, the highest level of adaptation potential in the given team has a project engineer equal to 0.68 and corresponds to the level of desirability good".

The presented approach has practical significance. It differs from the known identification of the parameters of self-regulation system, takes into account the influence of the main factors affecting the level of training. The higher the parameter of self-regulation of the system is, the higher the level of training and the stability of 
knowledge of the project team participants (their competitiveness). An algorithm for determining the self-regulation parameter of the system $\alpha_{k}$ is proposed, which shows the level of adaptation capabilities of the project team participant to increase the level of competence according to the IPMA standard ICB 4.0. The standardized score of each competence for three projects is defined and for each competence the self-regulation parameter $\alpha_{k}$ is defined. This parameter shows that it is most likely to increase this project manager's level of competencies "Strategy", "Time" and "Content", which is equal to 0.23 .

The proposed method of determining the adaptation potential provides an opportunity to track changes in the level of competence of each team member during the project, and change the structure, parameters and algorithms for acquiring knowledge, and determine the adaptive capabilities of team members during project work.

\section{ACKNOWLEDGEMENTS}

The research presented in this article is supported by Odessa National Polytechnic University (ONPU) and a research and production complex ZoryaMashproekt. The authors are grateful to the product development team of ONPU for their support and to Zorya-Mashproekt for the opportunity to participate in projects on gas and turbine equipment production.

\section{REFERENCES}

[1] A. E. Akgün, "Team wisdom in software development projects and its impact on project performance," International Journal of Information Management, 50, pp. 228-243, 2019. https://doi.org/10.1016/j.ijinfomgt.2019. 05.019

[2] T. Bjorvatn, A. Wald, "Project complexity and team-level absorptive capacity as drivers of project management performance," International Journal of Project Management, vol. 36, issue 6, pp. 876-888, 2018. https://doi.org/10.1016/j.ijproman.2018.5.003

[3] D. Monticolo, J. Badin, S. Gomes, E. Bonjour, "A meta-model for knowledge configuration management to support collaborative engineering," Computers in Industry, vol. 66, pp. 11-20, 2018. https://doi.org/10.1016/ j.compind.2014.08.001

[4] M. Ritou, F. Belkadi, Z. Yahouni, C. Da Cunha, F. Laroche, B. Furet, "Knowledgebased multi-level aggregation for decision aid in the machining industry," CIRP Annals, vol. 68, issue 1, pp. $475-478,2019$. https://doi.org/ 10.1016/j.cirp.2019.03.009
[5] W. Jun, W. Wei, D. Liting, J. Li, "Method for analyzing the knowledge collaboration effect of R\&D project teams based on Bloom's taxonomy," Computers \& Industrial Engineering, 103, pp. 158-167, 2017. https://doi.org/10.1016/j.cie.2016.11.010

[6] J. C.R., Tseng, H.-Ch. Chu, G.-J. Hwang, Ch.Ch. Tsai, "Development of an adaptive learning system with two sources of personalization information," Computers \& Education, 51, pp. 776-786, 2008. https://doi.org/10.1016/ j.compedu.2007.08.002

[7] P. Tomei, C.M. Verrelli, "Advances on adaptive learning control: The case of nonminimum phase linear systems," Systems \& Control Letters, vol. 115, pp. 55-62, 2018. https://doi.org/10.1016/j.sysconle.2018.03.006

[8] B. Chandra, Sh. K. Rajesh, "Deep learning with adaptive learning rate using Laplacian score," Expert Systems with Applications, vol. 63, pp. 1-7, 2016. https://doi.org/10.1016/j.eswa. 2016.05 .022

[9] V. Gogunskii, D. Lukianov, O. Vlasenko, "Identification of knowledge cores on a competence graph of project managers," Eastern-European Journal of Enterprise Technologies, no. 1(10(55)), pp. 26-28, 2012. http://dx.doi.org/10.15587/1729-4061.2012. 3487.

[10] B.H. Reich, A. Gemino, C. Sauer, "How knowledge management impacts performance in projects: An emperical study," International Journal of Project Management, 32, pp. 590602, 2014. https://doi.org/10.1016/j.ijproman. 2013.09.004

[11] A. Kuwertz, J. Beyerer, "Extending adaptive world modeling by identifying and handling insufficient knowledge models," Journal of Applied Logic, vol. 19, part 2, pp. 102-127, 2016. https://doi.org/10.1016/j.jal.2016.05.005

[12] Y. He, "A framework for IT-based knowledge management," Proceedings of the 2009 First IEEE International Conference on Information Science and Engineering, Nanjing, 2009, pp. 2794-2797. https://doi.org/10.1109/ICISE. 2009.35.

[13] S. Yu, L. Liu and M. Fu, "The application research on knowledge management of project manager," Proceedings of the 2009 IEEE International Conference on Information Management, Innovation Management and Industrial Engineering, Xi'an, 2009, pp. 340343, https://doi.org/10.1109/ICIII.2009.391.

[14] A Guide to the Project Management Body of Knowledge, 6th edition, PMI, 2017.

[15] S. Wan, D. Li, J. Gao, R. Roy, Yi. Tong, "Process and knowledge management in a 
collaborative maintenance planning system for high value machine tools," Computers in Industry, vol. 84, pp. 14-24, 2017. https://doi.org/10.1016/j.compind.2016.11.002.

[16] K. Venkitachalam, H. Willmott, "Strategic knowledge management - Insights and pitfalls," International Journal of Information Management, vol. 37, issue 4, pp. 313-316, 2017. https://doi.org/10.1016/j.ijinfomgt.2017. 02.002 .

[17] E.V. Kolesnikova, "Assessment of the competence of personnel furnace project of computer simulator," Eastern European Journal of Advanced Technologies, no. 5/1 (65), pp. $45-48,2013$.

[18] S. Lupuleac, Z.-L. Lupuleac, and C. Rusu, "Problems of assessing team roles balance team design," Procedia Economics and Finance, vol. 3, pp. 935-940, October 2012. doi: 10.1016/s2212-5671(12)00253-5.

[19] M. Caniëls, F. Chiocchio, and N. Van Loon, "Collaboration in project teams: The role of mastery and performance climates," International Journal of Project Management, nol. 37, pp. 1 - 13, 2019. https://doi.org/10. 1016/j.ijproman.2018.09.006.

[20] P. Różewski, and O. Zaikin, "Integrated mathematical model of competence-based learning/teaching process," Bulletin of the Polish Academy of Sciences. Technical Sciences, vol. 63, no 1, pp. 245-258, 2015.

[21] O. Dunets, C. Wolff, A. Sachenko, G. Hladiy, I. Dobrotvor, "Multi-agent system of IT project planning", Proceedings of the 9th IEEE International Conference on Intelligent Data Acquisition and Advanced Computing Systems: Technology and Applications (IDAACS), 2017, pp. 548-552. https://doi.org/10.1109/IDAACS. 2017.8095141 .

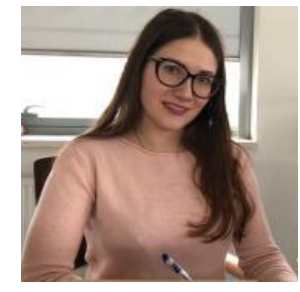

Olha Sherstiuk, Candidate of Engineering Sciences, Associate Professor of the Department of Management and Marketing. Scientific interests: project team building, knowledge management systems, emotional intelligence in project management, crossfunctional SCRUM teams.

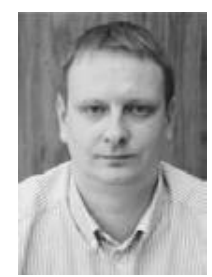

Oleksii Kolesnikov, Doctor of Engineering Sciences, Associate Professor, Associate Professor of the Department of Information Systems and Technology. Scientific interests: information technology in educational projects, project teambuilding, knowledge management.

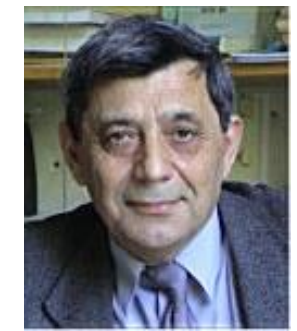

Viktor Gogunskii, Doctor of Engineering Sciences, Professor, Head of the Department of Vitality Protection Systems Management. Scientific interests: labor protection, life safety, ecology, information technologies in project manage-

ment, design of automated systems, knowledge management.

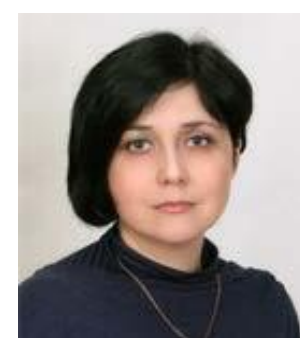

Kateryna Kolesnikova, Doctor of Engineering Sciences, Professor, Professor of the Department of Technology Management. Scientific interests: project management, knowledge management, modeling of complex objects and systems. 